Research Article

\title{
Seismic Performance Evaluation of Special RC Frames with Gravity Steel Columns under the Base Level
}

\author{
Amin Zaherdannak, ${ }^{1}$ Amirhosein Shabani $\mathbb{D}^{1,2}$ and Saeed Erfani ${ }^{1}{ }^{1}$ \\ ${ }^{1}$ Department of Civil and Environmental Engineering, Amirkabir University of Technology (Tehran Polytechnic), Tehran, Iran \\ ${ }^{2}$ Department of Civil Engineering and Energy Technology, Oslo Metropolitan University, Oslo, Norway \\ Correspondence should be addressed to Saeed Erfani; sderfani@aut.ac.ir
}

Received 4 March 2020; Revised 12 April 2020; Accepted 13 May 2020; Published 30 June 2020

Academic Editor: Roberto Palma

Copyright (c) 2020 Amin Zaherdannak et al. This is an open access article distributed under the Creative Commons Attribution License, which permits unrestricted use, distribution, and reproduction in any medium, provided the original work is properly cited.

\begin{abstract}
In many multistory buildings, basement levels are used as parking spaces. However, dimensions of reinforced concrete columns at these levels cause them to be unideal parking spaces. An alternative is to replace the RC columns in middle frames with steel columns that are not a part of seismic force resisting system and only support vertical loads, therefore have smaller sections. Using simply supported steel columns under the base level is beneficial not only because they have smaller cross-sections which lead to increasing the parking space but also these steel columns are easier to be replaced after any possible damages and can be considered as convenient alternatives compared to ordinary RC columns in construction. In this research, seismic performance of structures implementing the suggested alternative is evaluated using nonlinear static and dynamic analyses and compared to that of regular counterparts. Results show that these structures pass the acceptability tests proposed by FEMA P695 methodology. Moreover, seismic performance factors of these two structural systems have been calculated and proposed.
\end{abstract}

\section{Introduction}

To minimize casualties in large earthquakes, building codes provide structural engineers with seismic design requirements. This goal can be generally achieved by limiting the probability of global structural collapse of buildings to relatively low levels. However, not even total satisfaction of a building code provisions can necessarily mean that a building will meet certain performance objectives during large earthquakes. Compared to the intended performance objective of the building code, the performance exhibited by the building may or may not be adequate. Therefore, a methodology is needed for evaluating the performance of any given building designed based on requirements of a building code. The methodology introduced in FEMA P695 satisfies this need and it has been used in this study.

In the system, the performance of which is evaluated in this study, the upper part consists of special RC moment frames. Several research efforts have focused on developing methods to improve seismic design procedure of RC frames beyond minimum code requirements [1-3] and performance-based earthquake engineering is used to assess the effectiveness of these improvements $[4,5]$. Seismic collapse safety of ductile moment frames has been assessed by Haselton [6] and seismic collapse capacity of nonductile RC frames is evaluated and compared with ductile moment frames by Abbie et al. [7].

FEMA P695 introduces a methodology for quantification of building seismic performance factors used in seismic design and for specifying whether a structure satisfies the seismic performance objectives of building codes using the probabilistic assessment of collapse risk [8].

According to FEMA P695 methodology, Archetypes for nonlinear analyses must be selected so that they cover normal variations of key characteristics of structures [8], characteristics capable of affecting the overall seismic behavior of structures such as height and bay length. Then, archetypes with similarities in their structural behaviors and characteristics are classified into distinct performance groups. 
According to the ASCE 07-10, the base level location for the structures with basement walls without any openings and with compacted soil surrounding the walls is considered from ground floor, where the basement wall ends $[9,10]$.

This effort focuses on evaluating and comparing the performance of two types of structural systems varying in one aspect. At stories above the base level, both types consist of special RC moment frames and dual systems (special RC moment frames and special RC shear walls) on perimeter frames. The difference between two types is that, in one, the middle frames in basement levels are special RC moment frames, similar to stories above, but on the other, the columns in these middle frames are replaced with steel columns that are not a part of the SFRS. In this article, these two types of buildings will be referred to as RCT (Typical RC system) and RCN (New RC system), respectively.

Seismic performance of RC basement walls has been evaluated alone [11], and research studies about combining RC basement walls with special steel moment resisting frames have been conducted $[12,13]$, but seismic performance of RC frames with basement walls should be performed as a prevalent construction method.

Basement stories are often used as parking spaces and the relatively large dimensions of the RC columns in these levels, especially in buildings with shorter bay lengths, could prevent these levels from being ideal parking spaces. These RC columns can be replaced with gravity steel columns. Not being a part of SFRS and only bearing vertical loads, allows the steel columns in middle frames to have sections with relatively smaller dimensions and making these levels ideal for the intended use.

Moreover, in this paper, an innovative connection has been introduced for steel column-to-RC beam connections. Requiring only bolts and not any reinforcements or rebars and being relatively faster-to-fasten connections compared to traditional counterparts could make this connection preferable. Using only bolts, this connection can be easily detached or replaced after any damages.

Seismic performance factors for RCT and RCN models are not included in ASCE 07 Table 12-2.1. For designing structures with two structural systems in which the upper system is more flexible than the lower, ASCE 07 recommends a two-stage analysis. In this paper, the entire structure has been designed using only the seismic performance factors of special RC moment resisting frames instead of the recommended two-stage analysis. Results show that based on the FEMA P695 method, this alternative design does not negatively affect the performance of the structures [11].

For nonlinear models, lumped plasticity approach is used to model frame elements. Frame elements plastic hinges are modeled using a stiffness and strength degrading model developed by Ibarra et al. and modified by Lignos $[14,15]$.

\section{Designing Models}

A set of archetypical structures are employed in the assessment. These structures represent engineering design and practice for RCT and RCN systems in high seismic regions. 16 structural designs encompass key structural design parameters including building heights from 3 to 15 stories above the base level and from 2 to 5 basement levels, and bay widths of 4 and $7 \mathrm{~m}$ (13.12 to $22.97 \mathrm{ft}$.). As summarized in Table 1, for both RCN and RCT archetypes, this table is identical. All structures are space frame systems. These archetypes are classified into performance groups, each of which includes structures with relatively similar configuration and therefore structural behavior. Table 1 includes the fundamental period (CuTa, defined by Equation (5)-(5) of FEMA P695) $T$, the seismic base shear coefficient $C_{\mathrm{s}}$, and the maximum considered earthquake MCE-level spectral acceleration $\mathrm{S}_{\mathrm{MT}}[8]$.

All Archetypes are designed using response spectrum analysis procedure for seismic design category $D_{\max }$. Dead and live loads are applied to stories and static and dynamic soil loads are applied to basement walls according to ASCE 07-10 [9, 16]. A simplified method for considering the soilstructure interaction is used for designing the models that the soil is neglected but the wall is modeled. Each building is designed according to the provisions of ASCE 7-10, ACI 318-14, and AISC 360-10 [9, 17, 18] and all applicable requirements for detailing, stiffness, strength and capacity design are met, except for two-stage analysis procedure. As mentioned in ASCE 7-10, for structures having a flexible upper portion above a rigid lower portion, a two-stage analysis procedure can be used. This study intentionally does not implement this requirement and uses seismic design coefficients of RC SMFs for designing both upper and lower portions of the building. The validity of this assumption is put to test by FEMA P695 methodology. According to Table 12.2-1 in ASCE 07-10, design coefficient and factors are $R=8, C_{d}=5.5$, and $\Omega_{o}=3$ for RC SMFs and $R=7, C_{d}=5.5$, and $\Omega_{o}=2.5$ for special RC shear walls [9].

Detailing and in some cases, sections of RC frame elements above the base level are different in RCN archetypes compared to RCT counterparts. The reason is the incapability of RCN buildings to transfer moments to stories below the base level using RC columns of middle frames, since the steel columns located at basement levels are not a part of SFRS and can only provide support for gravity loads. Therefore, there is a different distribution of forces in RCN buildings. In middle frames, moments at both ends of $\mathrm{RC}$ columns at the first story above the base level have smaller values in RCN compared to their counterparts in RCT buildings. On the contrary, beams located at the first story and frame elements (both beam and column) and located at upper stories have larger moments in RCN buildings. The different distribution of forces leads to different detailing and section dimensions.

Steel columns have box sections and are connected to beams with simple connections. Figure 1 shows a schematic of these simple connections. By comparing the cross-section areas of the steel and $\mathrm{RC}$ middle columns under the base level, it has resulted that this substitution leads to approximately $84 \%$ (as a mean value for all the archetypes) of crosssection area reduction. 
TABLE 1: Archetype's configuration development and design properties for SBCC and RBCC archetypes.

\begin{tabular}{|c|c|c|c|c|c|c|c|c|}
\hline $\begin{array}{l}\text { No. of performance } \\
\text { groups }\end{array}$ & $\begin{array}{c}\text { Archetype design ID } \\
\text { number }\end{array}$ & $\begin{array}{c}\text { No. of SMF } \\
\text { stories }\end{array}$ & $\begin{array}{c}\text { No. of stories under the } \\
\text { base level }\end{array}$ & $\begin{array}{c}\text { No. of } \\
\text { spans }\end{array}$ & $\begin{array}{l}\text { Bay length } \\
(\mathrm{m})\end{array}$ & $\begin{array}{c}T \\
(\mathrm{sec}) \\
\end{array}$ & $\begin{array}{c}\mathrm{S}_{\mathrm{MT}} \\
(\mathrm{g})\end{array}$ & $C_{\mathrm{s}}$ \\
\hline 1 & $3 \mathrm{U} 2 \mathrm{~B} 3 \mathrm{~B} 4 \mathrm{mBL}$ & 3 & 2 & 3 & 4 & 0.55 & 1.5 & 0.125 \\
\hline \multirow[t]{2}{*}{2} & $3 \mathrm{U} 2 \mathrm{~B} 3 \mathrm{~B} 7 \mathrm{mBL}$ & 3 & 2 & 3 & 7 & 0.55 & 1.5 & 0.125 \\
\hline & 7U2B3B4mBL & 7 & 3 & 3 & 4 & 1.16 & 0.78 & 0.065 \\
\hline \multirow[t]{3}{*}{3} & 11U4B3B4mBL & 11 & 4 & 3 & 4 & 1.72 & 0.53 & 0.044 \\
\hline & 15U5B3B4mBL & 15 & 5 & 3 & 4 & 2.27 & 0.53 & 0.044 \\
\hline & 7U2B3B7mBL & 7 & 3 & 3 & 7 & 1.16 & 0.78 & 0.065 \\
\hline \multirow[t]{2}{*}{4} & 11U4B3B7mBL & 11 & 4 & 3 & 7 & 1.72 & 0.53 & 0.044 \\
\hline & $15 \mathrm{U} 5 \mathrm{~B} 3 \mathrm{~B} 7 \mathrm{mBL}$ & 15 & 5 & 3 & 7 & 2.27 & 0.53 & 0.044 \\
\hline
\end{tabular}

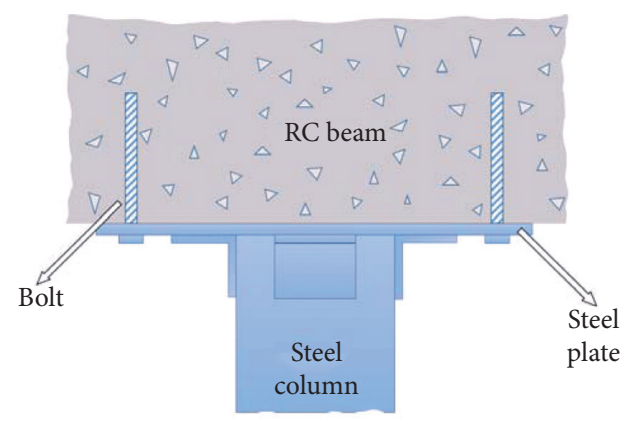

Figure 1: Schematic diagram of simple connections of steel columns in RCN archetypes.

\section{Nonlinear Model Development}

Figure 2 shows the nonlinear models created using OpenSees structural analysis platform. Having shear walls in basement levels, the outer frames display a different structural behavior compared to inner frames, therefore, neither can represent the behavior of the entire structure. One solution can be used to model two frames side-by-side to capture the behavior of both types of frames and their interactions. This solution eliminates the need for modeling leaning columns that capture the destabilizing $P-\Delta$ effects, since the gravity system (i.e., steel columns in basement levels) is directly modeled and the other frames are space frames [19]. These two adjacent frames in the OpenSees model are connected with hinged rigid elements (i.e., elastic element with a very high Young's modulus) that represent the slab connecting these frames together.

Damage reports of earthquakes including (1971) San Fernando and (1994) Northridge show that building basement walls have never been damaged due to soil seismic pressures [20]. Based on these reports, basement walls do not exhibit a nonlinear behavior in earthquakes; therefore, the basement walls are modeled as elastic elements using plane stress for node quadrilateral elements in OpenSees named QUAD with Young's modulus of concrete. The results also show that these levels undergo extremely small drifts during IDAs compared with nonbasement stories. Furthermore, for modeling segments of basement walls that can contribute to the response of modeled frames (i.e., parts of basement walls perpendicular to directly modeled basement walls) are modeled as elastic columns [21].

In this study, for models subjected to dynamic loads although the soil surrounding the retaining walls is not directly modeled, the effect of soil on the behavior of the structure is accounted for using another method. Based on this method, the soil is not modeled, and since the horizontal resistance of soil is ignored, the masses in subterranean floors are ignored as well [22-24].

The lumped plasticity models have gained more popularity for seismic response simulation of RC buildings $[8,25,26]$. Lumped plasticity elements were used because of their ability to capture rebar buckling and strain softening which are critical for simulating the collapse of RC frames. The plastic hinges of frame elements (i.e., beams and columns) are modeled using a stiffness and strength degrading model with a peak-oriented hysteretic response, developed by Ibarra et al. (2005) and modified by Lignos [14, 15, 25].

Figure 3 illustrates the backbone curve and cyclic behavior of the modified IMK (Ibarra Medina Krawinkler) in terms of a moment-rotation relationship. The backbone curve has three key parameters, namely, the elastic stiffness, postyield stiffness, and postcapping stiffness (strain softening). Postcapping stiffness and the displacement (ductility capacity) at which this softening occurs are the most important contributors affecting the seismic collapse capacity [6]. In the cyclic behavior of this model, the rate of cyclic deterioration depends on the deterioration parameter, which defines a reference energy-dissipation capacity for the component denoting the cumulative plastic rotation capacity $[15,27,28]$. Parameters for RC frame elements models are calibrated based on test data for RC columns with ductile detailing and low to moderate axial loads ATC 72 [24].

Modeling nonlinear behavior using plastic hinges when used in combination with Rayleigh damping could lead to unrealistically large damping forces in plastic hinges [29]. One solution for this problem is the approach taken by Ibarra and Media. In this approach, each beam element is modeled as a combination of an elastic beam and rotational end spring(s). These zero-length springs which do not have damping assigned to them are where the plastic hinging is concentrated. In this model, the ratio of the initial stiffness of end springs to the stiffness of elastic beam element is defined by the parameter $n$. Relatively large values of $n$ are chosen and therefore most of elastic deformation occurs in the elastic beam. All the damping is assigned to the elastic beam as an equivalent stiffnessproportional damping [30]. In this solution, relatively large values of $n$ are suggested [29]. Larger values of $n$ can make the numerical convergence in nonlinear analyses, a 

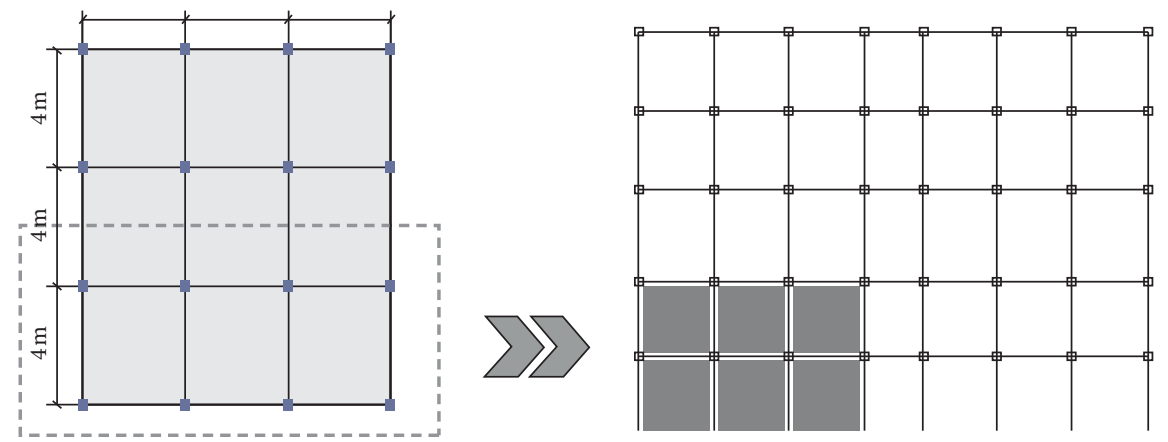

FIgURe 2: Plan view of archetypes and schematic nonlinear model of them.

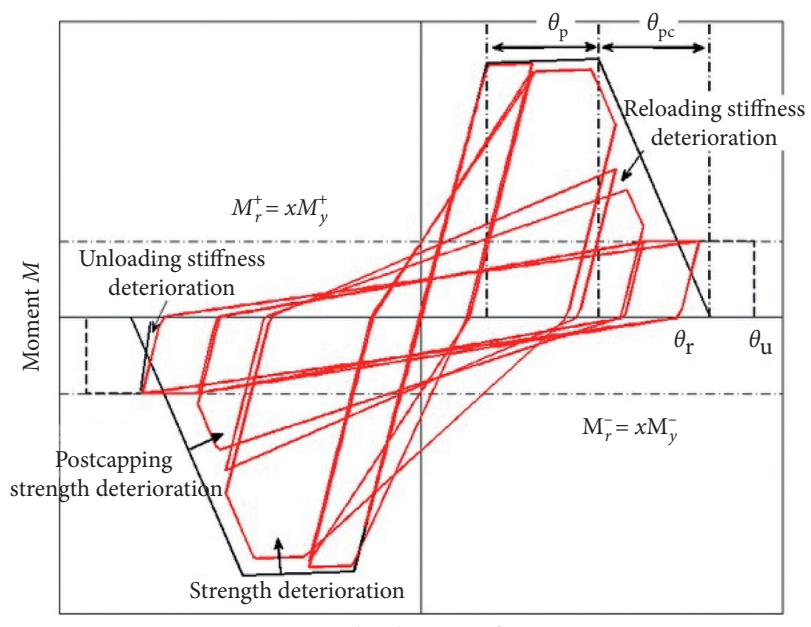

Chord rotation $\theta$

Figure 3: Backbone curve and cyclic behavior of the RC beamcolumn plastic hinge model [15].

more time-consuming and sometimes impossible process. Another issue is the assumption of end moments (in the original frame element) that are equal in value and sign which is not the case in earthquakes [30].

F. Zareian and H. Krawinkler (2009) have asserted by using elastic frame elements with stiffness modifiers, moment gradient problem is eliminated, and considerably smaller values of $n$ can be used, leading to less time-consuming numerical convergences in nonlinear analyses [30]. Therefore, in this study, all elements are modeled by elastic frame elements with stiffness modifiers and $n$ value equal to one.

Rayleigh damping is applied equal to $5 \%$ of critical damping in the first and third modes of the models. The Rayleigh damping stiffness-proportional term is assigned only to the elastic frame elements with stiffness modifiers while the mass-proportional term is assigned to all the frame nodes with mass $[6,31-33]$.

The nonlinear models of structures employ a two-dimensional joint model which was added to OpenSees framework by Altoontash. The joint model accounts for the finite joint size and includes a system of constraints and rotational springs for direct modeling of the shear panel and bond-slip behavior [8]. Figure 4 shows a schematic diagram of this model.

\section{Nonlinear Analyses}

4.1. Nonlinear Static Analysis (Pushover). Nonlinear static analysis (pushover) is performed for all archetypes by using a first mode lateral load pattern in accordance with Section 6.3, FEMA P695, in order to compute the system overstrength factor $\left(\Omega_{0}\right)$ and period-based ductility $\mu_{T}$. For a given index archetype, the overstrength factor, $\Omega$, is defined as the ratio of maximum shear resistance, $V_{\max }$, to the design base shear, $V$. For a given index archetype, the period-based ductility, $\mu_{T}$ is defined as the ratio of ultimate roof drift displacement, $\delta_{u}$, to the effective yield roof drift displacement $\delta_{y \text {,eff }}$. These parameters are shown in an idealized pushover curve in Figure 5. In order to quantify these values, the lateral loads are increasingly applied until a loss of $20 \%$ of the base shear capacity is achieved [8].

Pushover analysis provides insight into some of the nonlinear behavior aspects of structures. However, since the classical pushover analysis relies on constant lateral loads patterns, it is incapable of capturing the effects of higher modes. Therefore, it has been found to exhibit considerable deviations from inelastic demands during dynamic analyses and seismic events [34].

Figure 6 compares pushover curves for two models of $\mathrm{RCN}$ and RCT. In these figures, the base shear and roof drift are normalized by design base shear and building height, respectively.

RCN models exhibit higher maximum shear resistances compared to RCT models. The reason is different detailing and, in some models, different sections. Figure 7 shows plastic hinge distribution in some models when the structure is pushed to the ultimate roof drift displacement as defined in FEMA P695. The colors assigned to these plastic hinges indicate the severity of plastic hinging at these points. The color cyan for example indicates that a plastic hinge has undergone a rotation between 1 to 5 times larger than its yield rotation. Absence of a circle indicates a rotation smaller than the yield rotation.

As shown in Figure 7, RC beams located precisely above the topmost steel columns in RCN models undergo considerably more severe rotations. Since moments cannot be transferred from RC columns to the simply connected steel columns, these beams transfer the moments to outer frames, thus undergo larger forces and rotations. Moreover, in RCN 


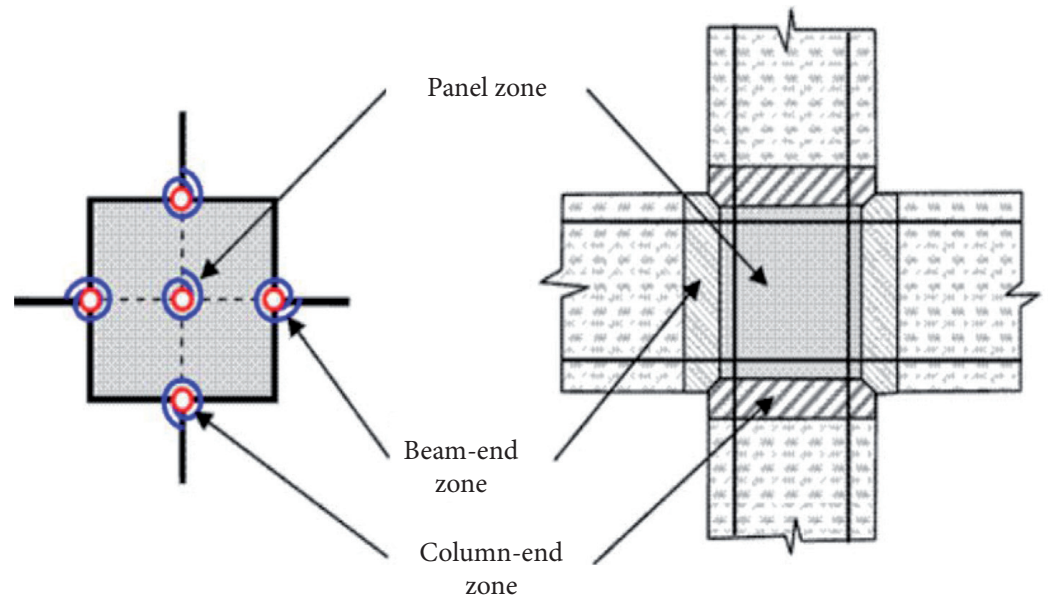

FIgURE 4: Schematic diagram of joint2D [8].

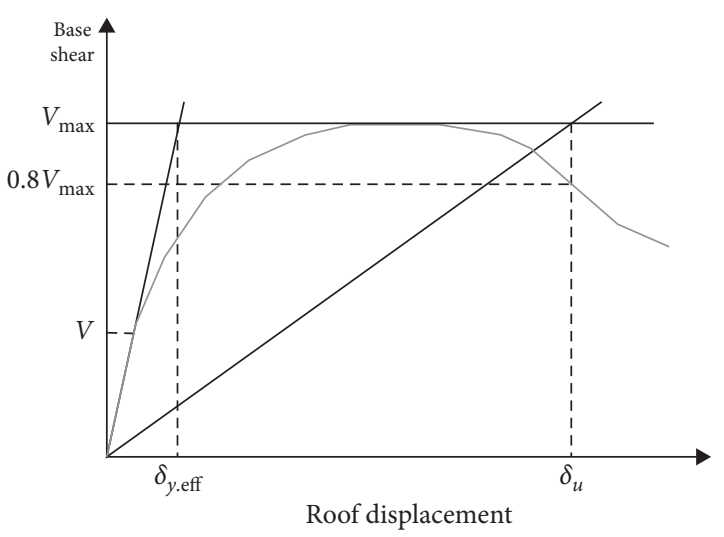

Figure 5: Idealized pushover curve [8].

building compared to RCT counterparts, plastic hinging occurs in more beams, and in most cases, it is more severe which reflects a different distribution of forces in frame elements.

4.2. Incremental Dynamic Analysis (IDA). IDA procedure recommended by FEMA P695 involves performing a series of nonlinear dynamic time-history analyses using 22 pairs of ground motion records [35]. Individual ground motions are scaled to increasing intensities until the structural model reaches a global collapse point. The lowest intensity at which half of the ground motions cause the structural model to collapse is the median collapse capacity, $S_{\mathrm{CT}}$. The ratio of $S_{\mathrm{CT}}$ to maximum considered earthquake (MCE) spectral acceleration at the fundamental period of each model $\left(S_{\mathrm{MT}}\right)$ defines the collapse margin ratio (CMR) of that model [8].

The results of these time-history analyses for one ground motion create a single IDA curve. An IDA curve is a diagram of the ground motion intensity measure (IM) against an engineering demand parameter (EDP). The spectral acceleration corresponding to the first mode elastic vibration period of the structure, $S_{a}\left(T_{1}\right)$, is a widely used ground motion IM and the chosen EDP is the maximum interstory drift [36-38].
For each archetype, a collapse fragility curve is defined using a cumulative distribution function, which relates the probability of collapse to the ground motion IM [39]. The standard deviation of natural logarithm and the median collapse capacity, $S_{\mathrm{CT}}$, are the parameters which define the collapse capacity [40].

Figure 8 shows IDA and 16, 50, and 84 percent fractile curves for some of the archetypes with RCN and RCT structural models as samples.

Figure 9 exhibits a comparison of the fragility curves of these two models. Results show that fragility curves of counterpart RCT and RCN models bear a close resemblance.

These fragility curves suggest that substituting RC columns with simply supported steel columns at basement stories does not negatively impact the seismic behavior of the structure [41].

\section{Performance Evaluation}

The most important parameter in FEMA P695 methodology is the adjusted collapse margin ratio (ACMR). Whether or not a specific structure satisfies the seismic performance objectives set by codes is determined using ACMR. This parameter is obtained by multiplying the CMR by spectral shape factor (SSF) for each structural model:

$$
\mathrm{ACMR}=\mathrm{SSF} \times \mathrm{CMR} .
$$

Baker and Cornell (2006) showed that rare ground motions in the western United States have a distinctive spectral shape that is different from the shape of the design spectrum in ASCE 7-10. The shape of these rare ground motions is peaked at the period of interest rapidly and drops at shorter and longer periods. Selecting a unique set of ground motions that have the appropriate shape for each site, hazard level and structural period of interest is not feasible; hence, FEMA P695 recommends using SSF-which is a function of fundamental period and period-based ductility-to remove this conservative bias [8].

Acceptable values of ACMR are based on total system collapse uncertainty, $\beta_{\mathrm{TOT}}$, and established acceptable values 


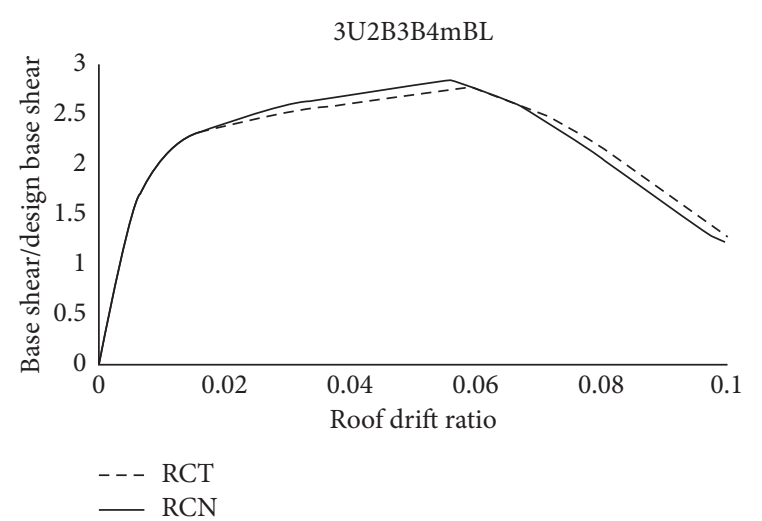

(a)

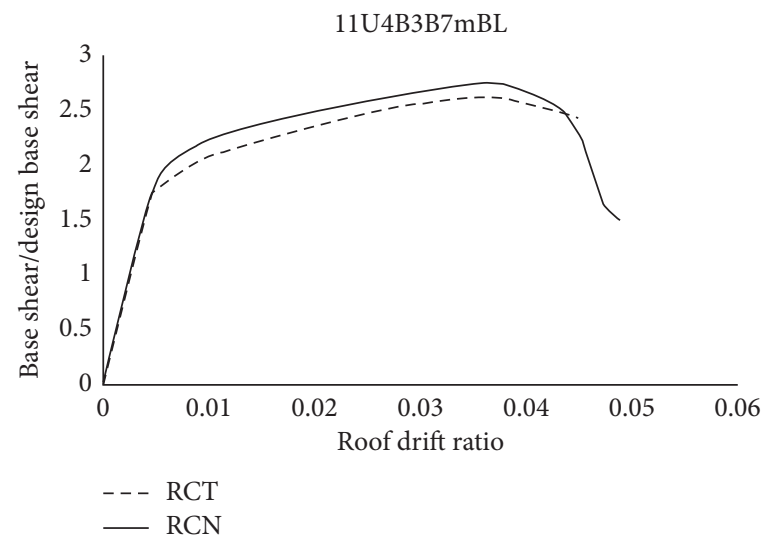

(c)

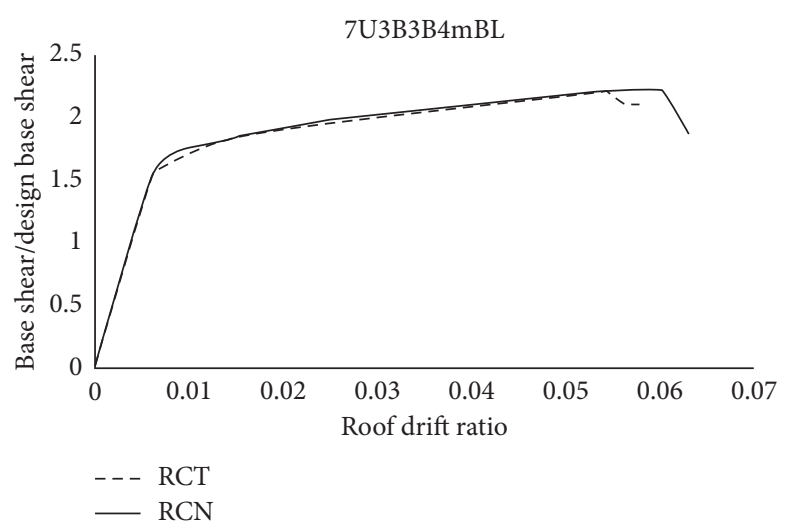

(b)

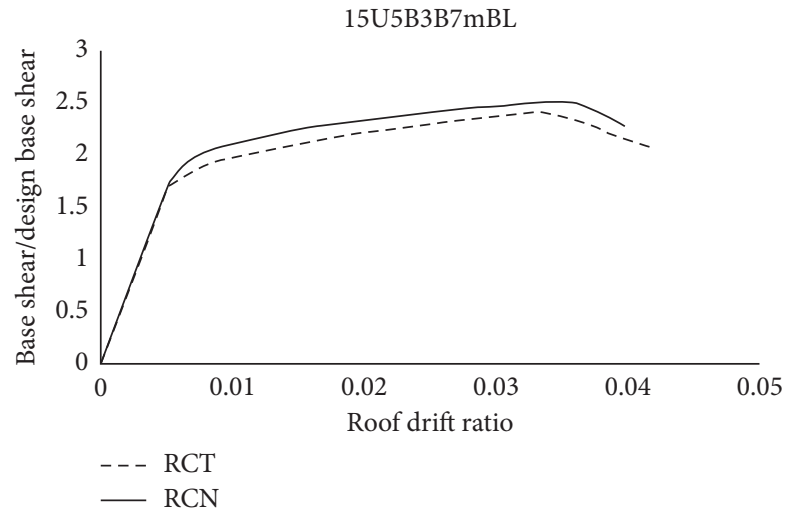

(d)

FIGURE 6: Normalized pushover curves comparison for some of the archetypes as samples for both RCN and RCT models.

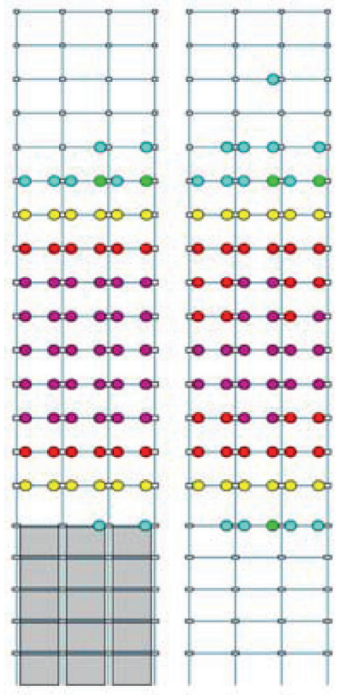

15 story $[\mathrm{RCT}]$

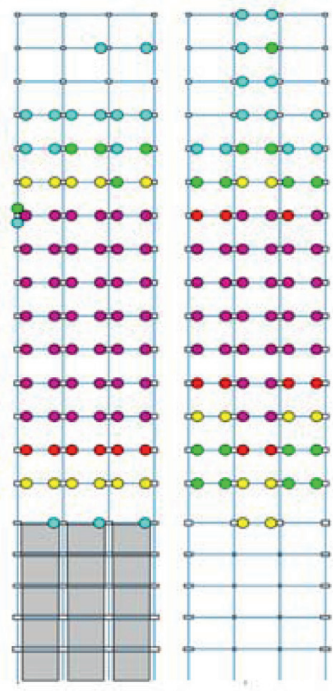

15 story $[\mathrm{RCN}]$

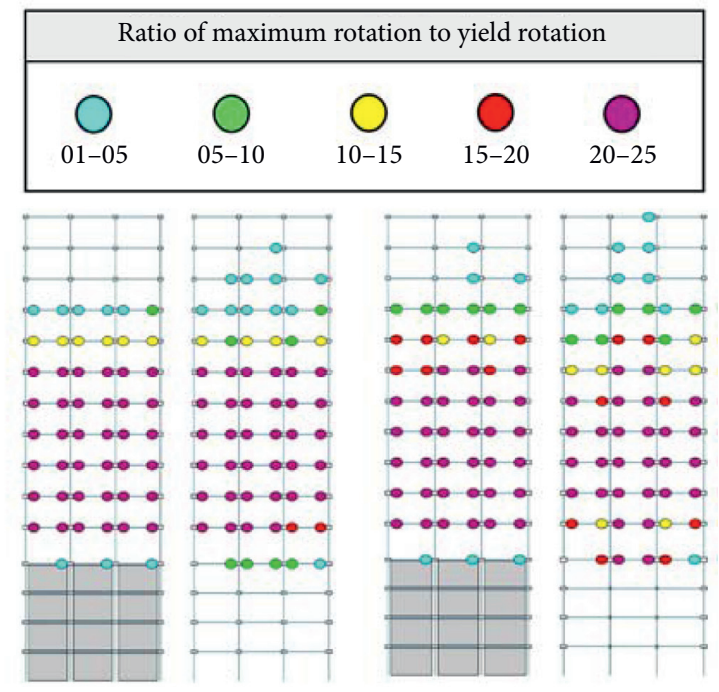

11 story [RCT]

11 story $[\mathrm{RCN}]$

FIGURE 7: Sideway collapse mechanism of archetype 11 and 15-story buildings with $4 \mathrm{~m}$-long bay lengths under pushover analysis to $\delta_{u}$

for probability of collapse. The total system collapse uncertainty is obtained using the following formula:

$$
\beta_{\mathrm{TOT}}=\sqrt{\beta_{\mathrm{RTR}}^{2}+\beta_{\mathrm{DR}}^{2}+\beta_{\mathrm{TD}}^{2}+\beta_{\mathrm{MLD}}^{2}}
$$

According to FEMA P695, in the performance evaluation of the systems with relatively large period-based ductilities $\left(\mu_{T} \geq 3\right)$, the constant value of 0.4 is considered for record-to-record uncertainty $\left(\beta_{\mathrm{RTR}}\right)$ [8]. 
RCT

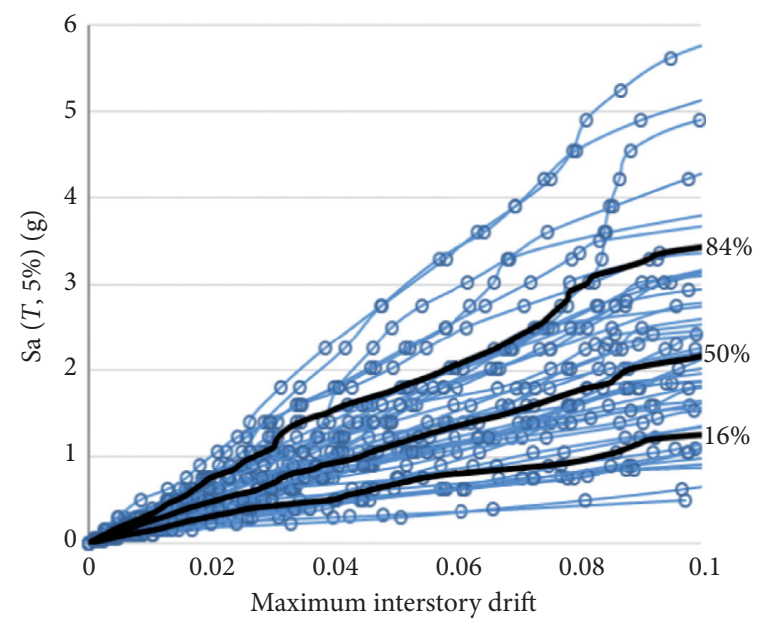

RCT

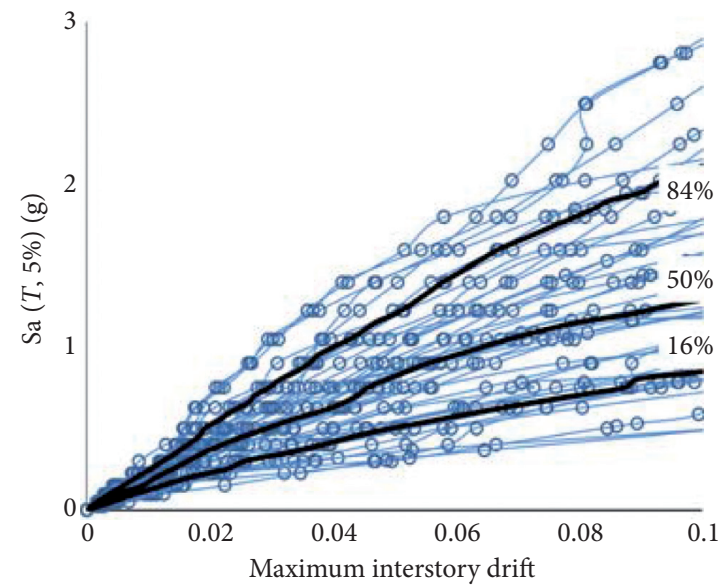

RCT

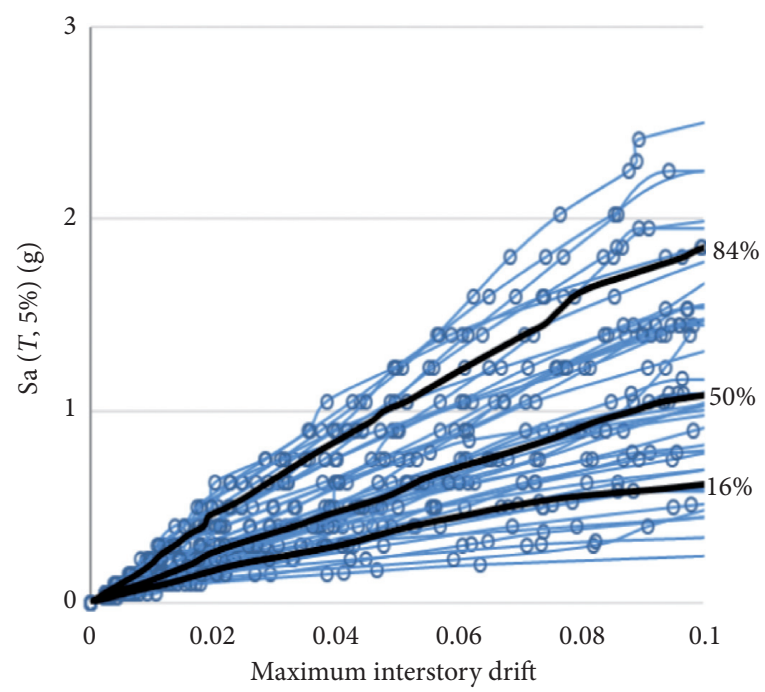

RCN

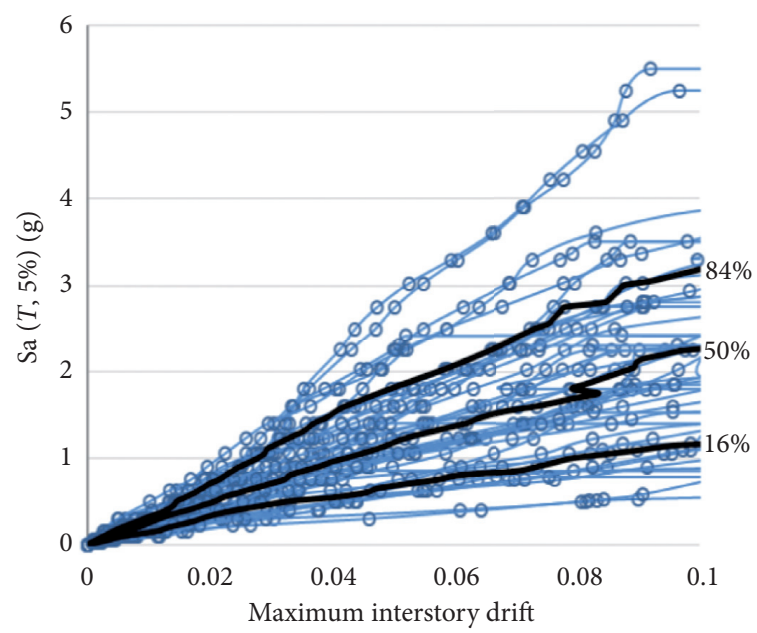

(a)

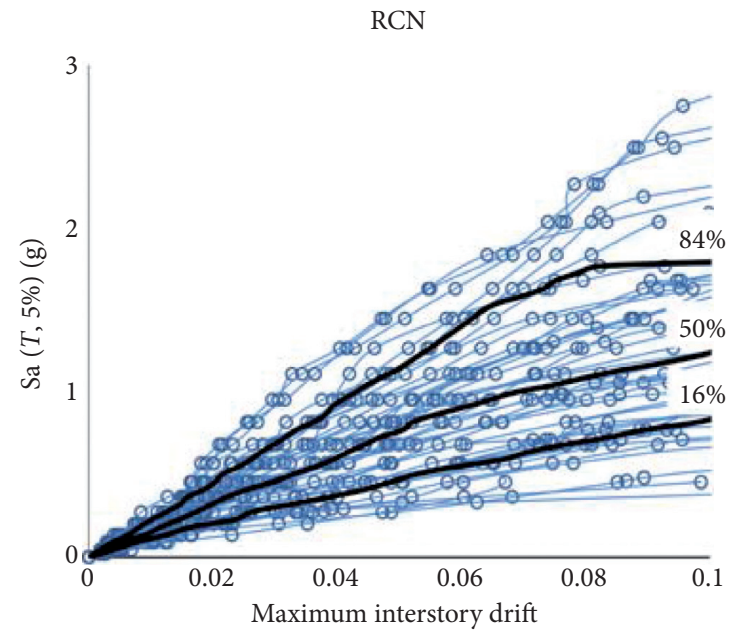

(b)

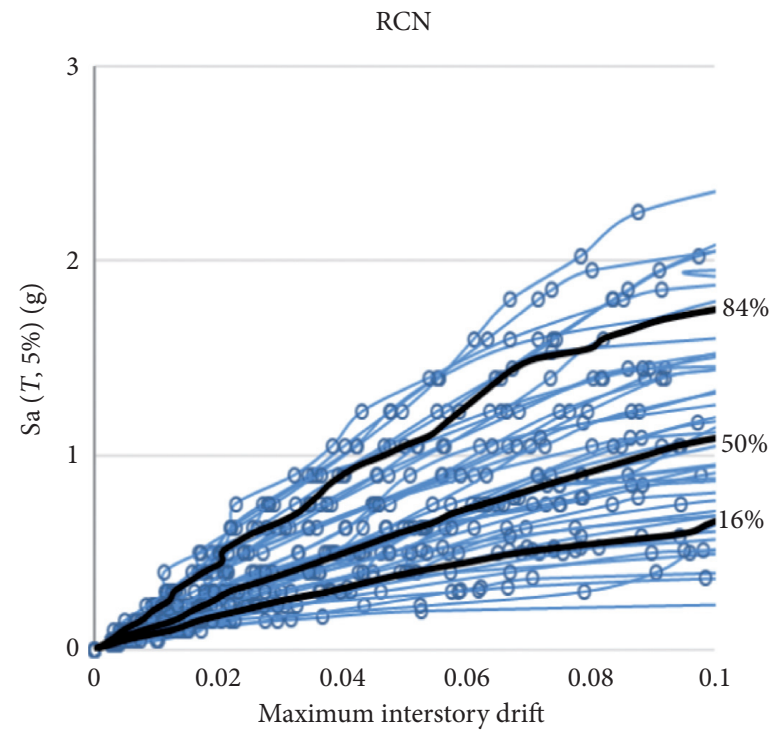

(c)

Figure 8: IDA and fractile curves of (a) 7U2B3B4mBL, (b) 11U4B3B7mBL, and (c) 15U5B3B7mBL for RCT and RCN models. 


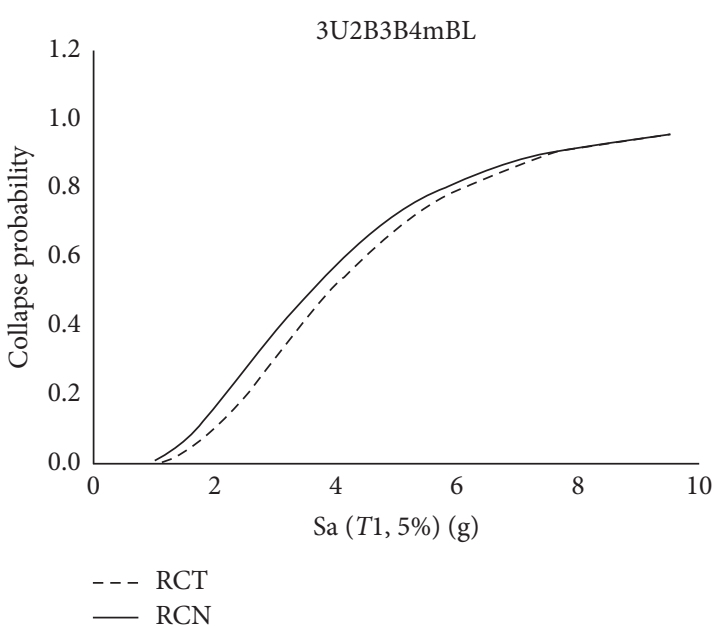

(a)

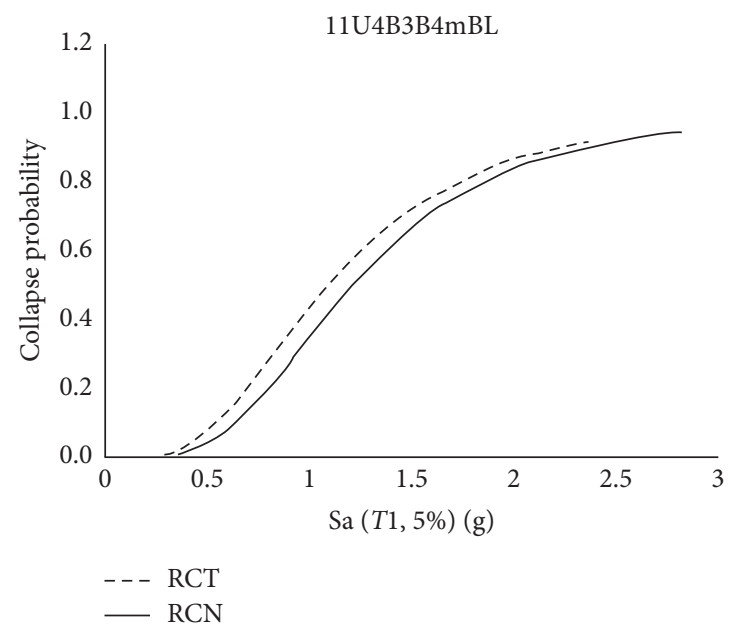

(c)

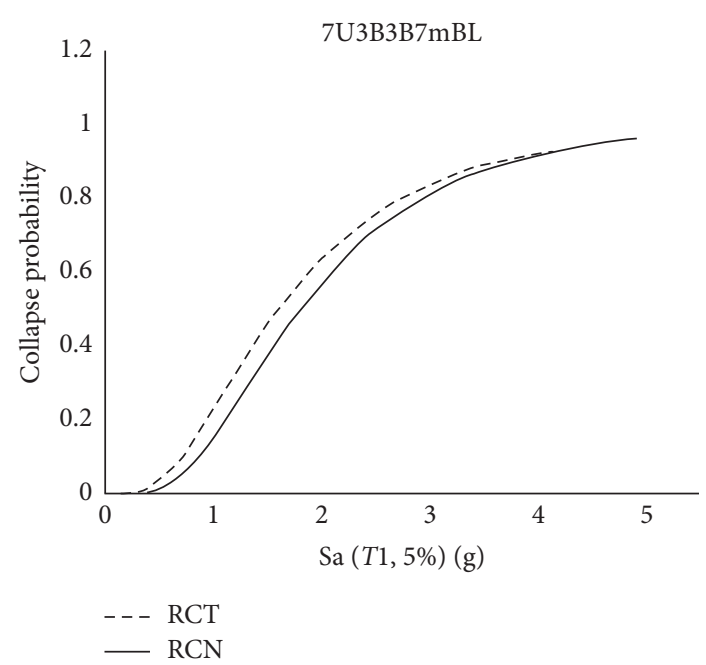

(e)

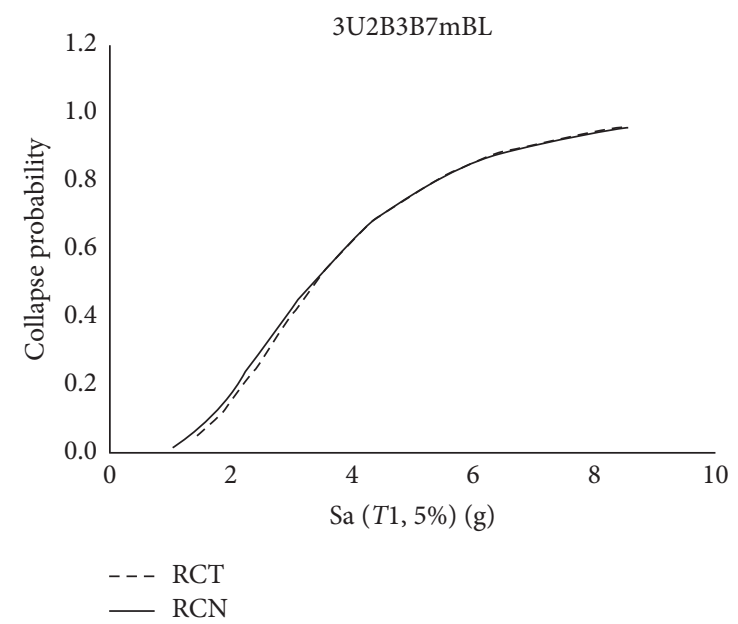

(b)

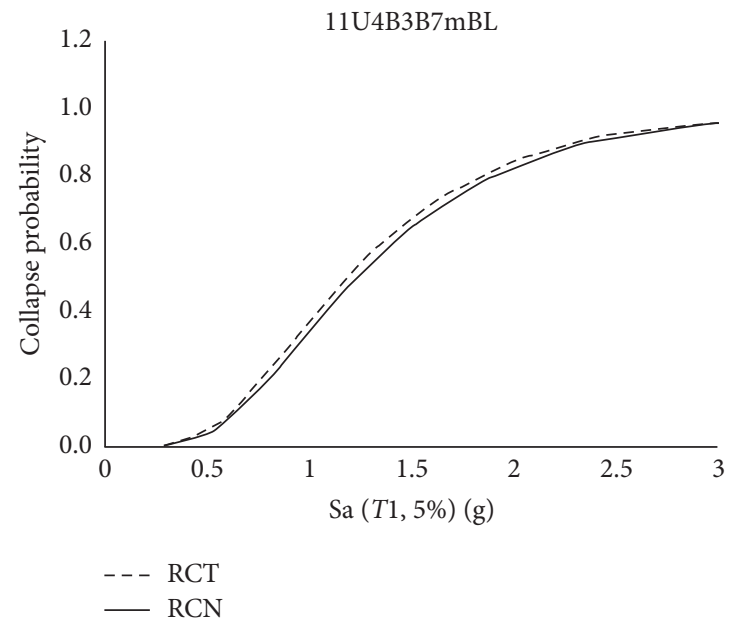

(d)

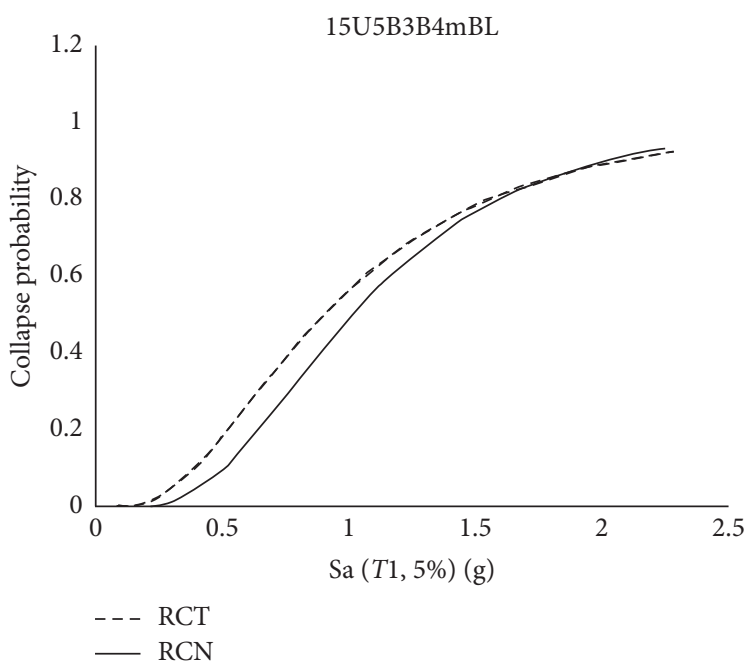

(f)

FIGURE 9: Fragility curves of some archetypes as samples for RCN and RCT models. 
TABLE 2: Collapse performance evaluation of RCT archetypes.

\begin{tabular}{|c|c|c|c|c|c|c|c|c|c|c|c|}
\hline $\begin{array}{l}\text { No. of performance } \\
\text { groups }\end{array}$ & $\begin{array}{c}\text { Archetype design ID } \\
\text { number }\end{array}$ & $\begin{array}{c}\text { No. of SMF } \\
\text { stories }\end{array}$ & $\Omega$ & $\mu_{t}$ & $S_{\mathrm{ct}}$ & $S_{\mathrm{mt}}$ & CMR & SSF & ACMR & $\begin{array}{l}\text { Accept } \\
\text { ACMR }\end{array}$ & $\begin{array}{l}\text { Pass or } \\
\text { fail }\end{array}$ \\
\hline 1 & 3U2B3B4mBL & 3 & 2.77 & 8.77 & 3.9 & 1.5 & 2.6 & 1.33 & 3.46 & 1.8 & $\mathrm{P}$ \\
\hline Group performance & & & 2.77 & & & & & & 3.46 & 2.45 & $\mathrm{P}$ \\
\hline 2 & $3 \mathrm{U} 2 \mathrm{~B} 3 \mathrm{~B} 7 \mathrm{mBL}$ & 3 & $\begin{array}{l}2.65 \\
2.65\end{array}$ & 7.88 & 3.33 & 1.5 & 2.22 & 1.33 & $\begin{array}{l}2.96 \\
2.96\end{array}$ & $\begin{array}{c}1.8 \\
2.45\end{array}$ & $\begin{array}{l}\mathrm{P} \\
\mathrm{P}\end{array}$ \\
\hline Group performance & 7U3B3B4mBL & 7 & 2.19 & 7.68 & 2.14 & 0.78 & 2.75 & 1.49 & 4.09 & 1.8 & $\mathrm{P}$ \\
\hline 3 & 11U4B3B4mBL & 11 & 2.08 & 7.53 & 1.17 & 0.53 & 2.21 & 1.6 & 3.54 & 1.8 & $\mathrm{P}$ \\
\hline & 15U5B3B4mBL & 15 & 1.72 & 8.28 & 0.98 & 0.53 & 1.85 & 1.5 & 2.77 & 1.8 & $\mathrm{P}$ \\
\hline Group performance & & & 1.99 & & & & & & 3.47 & 2.45 & $\mathrm{P}$ \\
\hline & 7U3B3B7mBL & 7 & 2.38 & 8.23 & 1.8 & 0.78 & 2.31 & 1.49 & 3.45 & 1.8 & $\mathrm{P}$ \\
\hline 4 & $11 \mathrm{U} 4 \mathrm{~B} 3 \mathrm{~B} 7 \mathrm{mBL}$ & 11 & 2.62 & 9.74 & 1.23 & 0.53 & 2.32 & 1.6 & 3.71 & 1.8 & $\mathrm{P}$ \\
\hline & 15U5B3B7mBL & 15 & 2.27 & 7 & 1.09 & 0.53 & 2.06 & 1.5 & 3.09 & 1.8 & $\mathrm{P}$ \\
\hline Group performance & & & 2.42 & & & & & & 3.41 & 2.45 & $\mathrm{P}$ \\
\hline
\end{tabular}

TABLE 3: Collapse performance evaluation of RCN archetypes.

\begin{tabular}{|c|c|c|c|c|c|c|c|c|c|c|c|}
\hline $\begin{array}{l}\text { No. of performance } \\
\text { group }\end{array}$ & $\begin{array}{c}\text { Archetype design ID } \\
\text { number }\end{array}$ & $\begin{array}{l}\text { No. of SMF } \\
\text { stories }\end{array}$ & $\Omega$ & $\mu_{t}$ & $S_{\mathrm{ct}}$ & $S_{\mathrm{mt}}$ & CMR & SSF & ACMR & $\begin{array}{l}\text { Accept } \\
\text { ACMR }\end{array}$ & $\begin{array}{c}\text { Pass or } \\
\text { fail }\end{array}$ \\
\hline 1 & 3U2B3B4mBL & 3 & 2.83 & 8.42 & 3.75 & 1.5 & 2.5 & 1.33 & 3.33 & 1.8 & $\mathrm{P}$ \\
\hline Group performance & & & 2.83 & & & & & & 3.33 & 2.45 & $\mathrm{P}$ \\
\hline 2 & 3U2B3B7mBL & 3 & 2.7 & 8.59 & 3.45 & 1.5 & 2.3 & 1.33 & 3.06 & 1.8 & $\mathrm{P}$ \\
\hline \multirow[t]{2}{*}{ Group performance } & & & 2.7 & & & & & & 3.06 & 2.45 & $\mathrm{P}$ \\
\hline & 7U3B3B4mBL & 7 & 2.23 & 8.78 & 2.25 & 0.78 & 2.89 & 1.49 & 4.31 & 1.8 & $\mathrm{P}$ \\
\hline \multirow[t]{2}{*}{3} & 11U4B3B4mBL & 11 & 2.47 & 7.14 & 1.23 & 0.53 & 2.32 & 1.6 & 3.71 & 1.8 & $\mathrm{P}$ \\
\hline & 15U5B3B4mBL & 15 & 2.16 & 7.24 & 1.09 & 0.53 & 2.06 & 1.5 & 3.09 & 1.8 & $\mathrm{P}$ \\
\hline \multirow[t]{2}{*}{ Group performance } & & & 2.27 & & & & & & 3.7 & 2.45 & $\mathrm{P}$ \\
\hline & 7U3B3B7mBL & 7 & 2.56 & 7.33 & 1.99 & 0.78 & 2.55 & 1.49 & 3.81 & 1.8 & $\mathrm{P}$ \\
\hline \multirow[t]{2}{*}{4} & $11 \mathrm{U} 4 \mathrm{~B} 3 \mathrm{~B} 7 \mathrm{mBL}$ & 11 & 2.74 & 7.88 & 1.23 & 0.53 & 2.32 & 1.6 & 3.71 & 1.8 & $\mathrm{P}$ \\
\hline & 15U5B3B7mBL & 15 & 2.38 & 6.61 & 1.05 & 0.53 & 1.99 & 1.5 & 2.98 & 1.8 & $\mathrm{P}$ \\
\hline Group performance & & & 2.56 & & & & & & 3.5 & 2.45 & $\mathrm{P}$ \\
\hline
\end{tabular}

ACI 318-14 design requirements have been utilized in this study. Since this code includes lessons learned from recent major earthquakes and represents many years of experiment and development, for assessing uncertainty according to FEMA P695 methodology, design requirements are categorized as superior $(A)$ and the value of 0.1 is considered for $\beta_{\mathrm{DR}}$.

The test data used in this article contain both cyclic and monotonic loading protocols and cover a wide range of column design configurations. Nevertheless, a number of these loading protocols are not continued to deformations large enough to observe strength loss. Moreover, these test data do not include beam elements with attached slabs. In addition, only column element tests were utilized for the calibration of the element model, while subassemblage tests and full-scale tests were not used. Considering the above observations, the test data are categorized as Good (B) and the value of 0.2 is assigned to $\beta_{\mathrm{TD}}$ [8].

Many detailing and capacity design requirements control RC frame buildings, which limits possible modes of failure. The primary expected mode of failure is flexural hinging leading to sideways collapse. By capturing postpeak degrading response under both cyclic and monotonic loading, the modeling approach can simulate flexural hinging and sideway collapse. Furthermore, the modeling approach can simulate structural response directly up to collapse point by simulating all expected modes of damage that could lead to collapse. However, despite being calibrated using column data, the model was not well calibrated to beam-slabs and it does not capture axial-flexural interaction in columns. Additionally, for modeling soil-structure interaction, a simplified method is used, and basement walls were assumed to remain elastic up to global collapse of the structure. Consequently, the modeling quality is categorized as $\operatorname{good}(\mathrm{B})$ and the value of 0.5 is assigned to $\beta_{\mathrm{MDL}}$.

Using values assigned to different sources of uncertainty discussed above, the total system collapse uncertainty of the structural models, $\beta_{\text {Tот }}$, is calculated to 0.675 . For the evaluation of the response modification coefficient based on FEMA P695 methodology, acceptable seismic performance is achieved when the average value of ACMR for each performance group exceeds the acceptable value of the ACMR corresponding to the collapse probability of $10 \%$ $\left(A C M R_{10 \%}\right)$ and individual value of ACMR for each archetype exceeds the acceptable value of the ACMR corresponding to the collapse probability of $20 \%\left(\mathrm{ACMR}_{20 \%}\right)$. Using Tables 7-3 in FEMA P695 and a total system collapse uncertainty, $\mathrm{ACMR}_{20 \%}$ and $\mathrm{ACMR}_{10 \%}$ values are found to be 1.76 and 2.38, respectively [8].

Tables 2 and 3 summarize the results obtained from numerous IDA and pushover analyses for both RCT and RCN structural models. 
Results show that all archetypes pass the acceptability check for seismic performance. The value of the system overstrength factor, $\Omega_{\mathrm{o}}$, for use in design should not be taken less than the largest average value of overstrength, $\Omega$, of any performance group. Based on the results summarized in tables above, 2.83 is the highest average value for overstrength; therefore, the overstrength of the system can be conservatively considered 3 , and the same value is specified in ASCE 7-10 for special RC moment frames [8].

\section{Conclusions}

In this study, typical RC columns in middle frames at basement levels are substituted with simply connected steel columns to make these levels more ideal parking spaces by decreasing the space occupied by structural elements, i.e., columns. Seismic performance of structures with RC columns (RCT) and those with the substituted steel columns at basement levels (RCN) was evaluated based on the FEMA P695 method. To evaluate the seismic performance of these structures, 16 archetypical structures where designed according to building codes, modeled in OpenSees platform and analyzed using pushover and IDA analyses.

Both RCT and RCN structures can be designed using response modification and overstrength factors 8 and 3 , respectively. In order to design either RCN or RCT structures, seismic performance factors of special RC frames $R=8, \mathrm{C}_{\mathrm{d}}=5.5$, and $\Omega_{\mathrm{o}}=3$ can be used for designing both upper and lower parts (i.e., special RC frames and dual systems) of the structure. In other words, the two-stage analysis procedure recommended by ASCE 7-10 does not need to be applied to neither RCN nor RCT structures. A regular one-stage analysis will suffice.

Inspecting plastic hinging occurrences in structural models when structures are pushed to effective yield drift in pushover analyses show that collector beams at the bottom of the first story above the base level of RCN archetypes are more prone to plastic hinging compared to their RCT counterparts. The reason is the different load paths in RCN buildings and the role these beams play in transferring forces from RC columns in middle frames to RC columns and walls in lower levels.

Because of different detailing and frame element sections in RC frames above the base level compared to RCT buildings, RCN structures have higher overstrength values.

RCN structures exhibit a similar or improved seismic performance compared to RCT building, therefore substituting RC columns by simply connected steel columns does not seem to negatively impact the overall behavior seismic of the structure.

\section{Data Availability}

The data used to support the findings of this study are available from the corresponding author upon request.

\section{Conflicts of Interest}

The authors declare that they have no conflicts of interest.

\section{References}

[1] I. Hajirasouliha, P. Asadi, and K. Pilakoutas, "An efficient performance-based seismic design method for reinforced concrete frames," Earthquake Engineering \& Structural Dynamics, vol. 41, no. 4, pp. 663-679, 2012.

[2] J. Bai, S. Jin, C. Zhang, and J. Ou, "Seismic optimization design for uniform damage of reinforced concrete momentresisting frames using consecutive modal pushover analysis," Advances in Structural Engineering, vol. 19, no. 8, pp. 13131327, 2016.

[3] M. Ahmed, S. Tayyaba, and M. W. Ashraf, "Effect of buckling restrained braces locations on seismic responses of high-rise RC core wall buildings," Shock and Vibration, vol. 2016, Article ID 6808137, 15 pages, 2016.

[4] O. Arroyo, A. Liel, and S. Gutiérrez, "A performance-based evaluation of a seismic design method for reinforced concrete frames," Journal of Earthquake Engineering, vol. 22, pp. 1-18, 2017.

[5] D. Tao, Q. Ma, and S. Li, "Seismic damage detection of moment resisting frame structures using time-frequency features," Shock and Vibration, vol. 2018, Article ID 1086540, 18 pages, 2018.

[6] C. B. Haselton, "Seismic collapse safety of reinforced concrete buildings. I: assessment of ductile moment frames," Journal of Structural Engineering, vol. 137, no. 4, pp. 481-491, 2010.

[7] A. B. Liel, C. B. Haselton, and G. G. Deierlein, "Seismic collapse safety of reinforced concrete buildings. II: comparative assessment of nonductile and ductile moment frames," Journal of Structural Engineering, vol. 137, no. 4, pp. 492-502, 2010.

[8] Fema, Quantification of Building Seismic Performance Factors (FEMA P695), Federal Emergency Management Agency, Washington, D.C., USA, 2009.

[9] ASCE, Design Loads For Buildings And Other Structures, ASCE/SEI 7-10, American Sociey of Civil Engineers, Reston, VA, USA, 2010.

[10] M. Tehranizadeh and M. S. Barkhordari, "Effect of peripheral wall openings in basement and number of basement floors on the base level of braced framed tube system," International Journal of Civil Engineering, vol. 16, 2017.

[11] J. Lee and J. Kim, "Seismic performance evaluation of staggered wall structures using Fema P695 procedure," Magazine of Concrete Research, vol. 65, no. 17, pp. 1023-1033, 2013.

[12] A. Shabani and S. Erfani, "Evaluation of seismic performance factors of special steel moment resisting frames with basement walls," in Proceedings of the 3rd International Conference of Steel and Structure, Tehran Iran, December 2018.

[13] A. Shabani and S. Erfani, "Seismic performance evaluation of SSMF with simple beam-column connections under the base level," International Journal of Steel Structures, vol. 20, pp. 1-12, 2019.

[14] L. F. Ibarra, R. A. Medina, and H. Krawinkler, "Hysteretic models that incorporate strength and stiffness deterioration," Earthquake Engineering \& Structural Dynamics, vol. 34, no. 12, pp. 1489-1511, 2005.

[15] D. Lignos and H. Krawinkler, Sidesway Collapse of Deteriorating Structural Systems under Seismic Excitations, Stanford university, Stanford, CA, USA, 2012.

[16] N. Sitar, R. G. Mikola, and G. Candia, "Seismically induced lateral earth pressures on retaining structures and basement walls," in Proceedings of the Geotechnical Engineering State of the Art and Practice: Keynote Lectures from GeoCongress, pp. 335-358, Oakland, CA, USA, 2012. 
[17] AISC, Seismic Provisions for Structural Steel Buildings (ANSI/ AISC 341-10), American Institute of Steel Construction, Chicago, IL, USA, 2010.

[18] ACI, Building Code Requirements for Structural Concrete ACI 318-14, American Concrete Institute, Farmington Hills, Michigan, USA, 2014.

[19] A. Elkady and D. G. Lignos, "Modeling of the composite action in fully restrained beam-to-column connections: implications in the seismic design and collapse capacity of steel special moment frames," Earthquake Engineering \& Structural Dynamics, vol. 43, no. 13, pp. 1935-1954, 2014.

[20] M. Lew, N. Sitar, L. Al Atik, M. Pourzanjani, and M. B. Hudson, "Seismic earth pressures on deep building basements," in Proceedings of the Structural Engineers Association of California Annual Convention Proceedings, Indian Wells, CA, USA, 2010.

[21] S. Mazzoni, OpenSees Command Language Manual, Open System for Earthquake Engineering Simulation (OpenSees), New York, NY, USA, 2006.

[22] Fema, NEHRP Recommended Seismic Provisions for New Buildings and Other Structures FEMA P-750, Federal Emergencey Management Agency, Washington, D.C., USA, 2009.

[23] TBI, Guidelines for Performance-Based Seismic Design of Tall Buildings, Tall Building Initiative, New York, NY, USA, 2010.

[24] PEER/ATC, Modeling and Acceptance Criteria for Seismic Design and Analysis of Tall Buildings (ATC 72-1), Applied Technology Council, Pacific Earthquake Engineering Research Center, Bekley, CA, USA, 2010.

[25] S. Manie, A. S. Moghadam, and M. Ghafory-Ashtiany, "Collapse behavior evaluation of asymmetric buildings subjected to bi-directional ground motion," The Structural Design of Tall and Special Buildings, vol. 24, no. 8, pp. 607-628, 2015.

[26] M. Surana, Y. Singh, and D. H. Lang, "Fragility analysis of hillside buildings designed for modern seismic design codes," The Structural Design of Tall and Special Buildings, Article ID e1500, 2018.

[27] B. U. Gokkaya, J. W. Baker, and G. G. Deierlein, "Estimation and impacts of model parameter correlation for seismic performance assessment of reinforced concrete structures," Structural Safety, vol. 69, pp. 68-78, 2017.

[28] D. G. Lignos and H. Krawinkler, "Development and utilization of structural component databases for performancebased earthquake engineering," Journal of Structural Engineering, vol. 139, no. 8, pp. 1382-1394, 2012.

[29] L. F. Ibarra and H. Krawinkler, Global Collapse of Frame Structures under Seismic Excitaions, Stanford university, Stanford, CA, USA, 2005.

[30] F. Zareian and H. Krawinkler, Simplified Performance Based Earthquake Engineering, Stanford university, Stanford, CA, USA, 2009.

[31] F. Zareian and R. A. Medina, "A practical method for proper modeling of structural damping in inelastic plane structural systems," Computers \& Structures, vol. 88, no. 1-2, pp. 45-53, 2010.

[32] A. K. Chopra and F. McKenna, "Modeling viscous damping in nonlinear response history analysis of buildings for earthquake excitation," Earthquake Engineering \& Structural Dynamics, vol. 45, no. 2, pp. 193-211, 2016.

[33] F. A. Charney, "Unintended consequences of modeling damping in structures," Journal of Structural Engineering, vol. 134, no. 4, pp. 581-592, 2008.

[34] M. AlHamaydeh, S. Abdullah, A. Hamid, and A. Mustapha, "Seismic design factors for RC special moment resisting frames in Dubai, UAE," Earthquake Engineering and Engineering Vibration, vol. 10, no. 4, pp. 495-506, 2011.

[35] Z. He, Z. Wang, and Y. Zhang, "Collapse safety margin and seismic loss assessment of RC frames with equal material cost," The Structural Design of Tall and Special Buildings, vol. 27, no. 1, p. e1407, 2018.

[36] D. Vamvatsikos and C. A. Cornell, "Applied incremental dynamic analysis," Earthquake Spectra, vol. 20, no. 2, pp. 523-553, 2004.

[37] D. Vamvatsikos, Seismic Performance, Capacity and Reliability of Structures as Seen through Incremental Dynamic Analysis, Stanford university, Stanford, CA, USA, 2012.

[38] Y. Jiang, "Seismic performance of composite structures made with concrete-filled steel tubular members," in Proceedings of the 16ECEE- 16th European Conference on Earthquake Engineering, Thessaloniki, Greece, June 2018.

[39] F. Zareian and H. Krawinkler, "Assessment of probability of collapse and design for collapse safety," Earthquake Engineering \& Structural Dynamics, vol. 36, no. 13, pp. 1901-1914, 2007.

[40] K. Porter, "Beginner's guide to fragility, vulnerability, and risk," Encyclopedia of Earthquake Engineering, pp. 235-260, Springer, Berlin, Germany, 2015.

[41] M. Zaker Esteghamati, M. Banazadeh, and Q. Huang, "The effect of design drift limit on the seismic performance of RC dual high-rise buildings," The Structural Design of Tall and Special Buildings, vol. 27, no. 8, Article ID e1464, 2018. 